\title{
Apoptosis and apoptosis related gene expression in normal conjunctiva and pterygium
}

\author{
Donald T H Tan, Wen Ying Tang, Yan Ping Liu, Hak-Su Goh, Duncan R Smith
}

\begin{abstract}
Background-Pterygium is a relatively common eye disease in the tropics whose aetiology and pathogenesis remain uncertain. As such, interest has focused on understanding the underlying mechanism of pterygia development.

Methods-15 specimens of pterygia from 15 eyes were examined, together with normal conjunctival tissue from the same eyes for the pattern of gene expression of genes associated with the induction or repression of apoptosis (p53, bcl-2, and bax). In addition, the samples directly for apoptotic cells were examined by the terminal deoxynucleotide transferase (TdT) mediated nick end labelling (TUNEL) methodology.

Results-In pterygia specimens apoptotic cells were found mainly confined to the basal layer of cells of the epithelial layer, situated immediately adjacent to the fibrovascular support layer. These cells were shown to express significant levels of p53 and bax, as well as the apoptosis inhibiting protein bcl-2. In contrast, normal conjunctival specimens displayed no bcl-2 expression and apoptotic cells were seen throughout the entire width of the epithelial layer, coupled with high levels of bax expression.
\end{abstract}

Conclusion-These results support a model whereby pterygia development is a result of disruption of the normal process of apoptosis occurring in the conjunctiva. (Br F Ophthalmol 2000;84:212-216)

Pterygium is a condition characterised by a triangular or wing-shaped overgrowth of abnormal conjunctiva onto the cornea, and it is prevalent in periequatorial and tropical regions. In severe cases, visual loss may arise from induced irregular corneal astigmatism, corneal stromal scarring, and obscuration of the visual axis, while ocular irritation often occurs as a result of ocular surface inflammation at the site of the pterygium. ${ }^{12}$ While considered a relatively benign condition, pterygia can be locally invasive and can exhibit varying degrees of abnormality ranging from mild dysplasia to carcinoma in situ. ${ }^{3}$

Originally believed to be a degenerative condition of the conjunctivae, recent thinking has tended to consider this disease as a growth disorder. ${ }^{45}$ Because of this, many treatment options, including a wide excision of the lesion, the administration of adjuvant radiotherapy, and antimitotic chemotherapy, mimic those employed for tumour treatment. In further parallel to neoplastic disorders, pterygium can recur aggressively, often within a matter of months in a high proportion of cases. Interestingly, the rate of recurrence is highly correlated with surgical treatment strategy, and most recent surgical trials have evaluated the use of free conjunctival autografts, or modified variants to address the problem of recurrence. ${ }^{67}$ While little is known about the cause of pterygia, several factors including male sex, outdoor occupation, and advanced age have been associated with an increased incidence of pterygium. ${ }^{8}$ Exposure to sunlight, and in particular reflected sunlight, both during childhood $^{9}$ and in later life has been implicated in the subsequent development of pterygia. ${ }^{9-11}$ It has been proposed that similar to certain skin malignancies it is the ultraviolet component that is the primary causative agent. ${ }^{9}$ Pterygia can develop in either one eye or bilaterally, and in the majority of cases, development proceeds along the nasotemporal axis.

The aetiology of pterygium is largely unknown. Two reports have detected chromosomal allelic loss in slightly over $50 \%$ of specimens studied as well as a low frequency of microsatellite instability. ${ }^{12}{ }^{13}$ Another report has presented evidence for the overexpression of the p53 tumour suppressor gene in both pterygia samples as well as normal conjunctival epithelia from the same eyes, ${ }^{4}$ while other authors have detected p53 overexpression only in pterygium samples. ${ }^{5}$

Maintenance of cellular homeostasis is essentially regulated by two processes - cellular proliferation and cellular apoptosis. One earlier study has demonstrated similar cellular proliferation patterns between pterygia and conjunctival tissues. ${ }^{8}$ If then, pterygium is not a disorder of excess cellular proliferation, it is possible that it results from a failure of appropriate cellular apoptosis. To explore this possibility we have examined pterygia specimens for the pattern of expression of genes known to be involved in the regulation (both positively and negatively) of apoptosis, as well as looking directly for apoptotic cells.

Materials and methods

PATIENTS AND SPECIMENS

Pterygia samples and normal conjunctival specimens were harvested from patients undergoing pterygium excision with conjunctival autografting $^{6}$ after informed consent was given. Normal conjunctiva was obtained from the superior conjunctiva at the site of conjunctival graft harvesting. Samples were flash frozen in liquid nitrogen at the time of surgery, and stored at $-80^{\circ} \mathrm{C}$ until required. Before analysis, 
all specimens were embedded in OTC freezing medium and sectioned into $5 \mu \mathrm{m}$ sections on a cryostat at $-20^{\circ} \mathrm{C}$ and transferred onto poly-Llysine treated slides. There were 13 primary and two recurrent pterygia specimens in this cohort.

TUNEL ANALYSIS

Sections for terminal deoxynucleotide transferase (TdT) mediated nick end labelling (TUNEL) ${ }^{14}$ were brought to room temperature and fixed in a $4 \%$ solution of paraformaldehyde. TUNEL analysis was undertaken with the cell death kit (Boehringer Mannheim $\mathrm{GmbH}$, Penzburg, Germany) essentially as recommended by the manufacturer. Briefly, tissue sections were incubated with $25 \mu \mathrm{g} / \mathrm{ml}$ proteinase $\mathrm{K}$ in $10 \mathrm{mM}$ TRIS- $\mathrm{HCl}, \mathrm{pH} 7.4$, for 15 minutes at room temperature. Following rinsing in phosphate buffered saline (PBS), exogenous peroxidases were quenched in 3\% hydrogen peroxide for 5 minutes. After rinsing in PBS, slides were incubated in blocking solution for 30 minutes at room temperature. Slides were incubated with $100 \mu \mathrm{l}$ of the TUNEL reaction mixture for 60 minutes at room temperature in a humidified atmosphere. Following rinsing in PBS slides were incubated with $100 \mu \mathrm{l}$ converter peroxidase solution, prediluted 1:5 in blocking solution and incubated for a further 30 minutes at room temperature. After rinsing in PBS samples were incubated with $1 \mathrm{mg} / \mathrm{ml} \mathrm{3,3'-diaminobenzidine} \mathrm{tetrahy-}$ drochloride (DAB; Dako) and incubated for 8 minutes at room temperature. Slides were subsequently washed, counterstained with haematoxylin, and mounted.

\section{IMMUNOHISTOCHEMISTRY}

Immunoreactive p53, bcl-2, and bax were detected by the labelled streptavidin-biotin method. ${ }^{15}$ Sections were allowed to come to room temperature and then dehydrated in acetone for 10 minutes at $-20^{\circ} \mathrm{C}$. Following extensive rinsing in PBS endogenous peroxidases were quenched in 3\% hydrogen peroxide for 5 minutes. After washing in PBS slides were then incubated with blocking reagent for 20 minutes (Dako LSAB Kit, Dako Carpinteria, CA, USA).
Incubation with primary antibody followed rinsing three times with PBS. Incubation was undertaken at $4^{\circ} \mathrm{C}$ overnight with either a 1:100 dilution of anti-p53 monoclonal antibody DO7 (Dako); a 1:100 dilution of anti-bcl-2 polyclonal antibody Ab-2 (Oncogene Research Products, Cambridge, MA, USA) or a 1:100 dilution of anti-bax polyclonal antibody AB-1 (Oncogene Research Products). Following three rinses with PBS, slides were then incubated with linking antibody (Dako) for 10 minutes, followed by 10 minutes with streptavidin-horseradish peroxidase diluted as recommended by the manufacturer and then incubated for 8 minutes with $\mathrm{DAB}$ (Dako). After each incubation samples were rinsed three times with PBS. Samples were counterstained with haematoxylin for 1 minute and nuclei blued in water. Slides were then dehydrated and mounted.

\section{Results}

We have examined the pattern of expression of the apoptosis related genes p53, bcl-2, and bax in 15 samples of pterygia from 15 eyes, as well as sections of normal conjunctivae from the same eyes. At the same time we examined the samples directly for evidence of apoptotic or pre-apoptotic cells using the TUNEL methodology. Results are summarised in Table 1.

\section{TUNEL ANALYSIS}

The epithelial layers of all the samples examined were positive by the TUNEL analysis (Table 1), indicating the presence of apoptotic cells. A significant difference was noted, however, in the distribution of TUNEL positive cells. In the epithelial layer of the pterygia specimens, the TUNEL positive cells were mainly restricted to a single layer of basal epithelial cells. In contrast, TUNEL positive cells are found throughout the thickness of the epithelial layer in the normal conjunctival specimens from the same eyes (Fig 1). The fibrovascular layer of both pterygia and normal conjunctivae show a more heterogenous pattern with $85 \%(13 / 15)$ of pterygia and $67 \%$ $(10 / 15)$ of normal conjunctival fibrovascular layers showing evidence of apoptotic cells

Table 1 Results of immunohistochemical and TUNEL analysis for 15 pterygia specimens together with matched superior bulbar conjunctivae from the same eyes

\begin{tabular}{|c|c|c|c|c|c|c|c|c|c|c|c|c|c|c|c|c|}
\hline \multirow[b]{3}{*}{ Patient } & \multicolumn{8}{|c|}{ Pterygium } & \multicolumn{8}{|c|}{ Conjunctiva } \\
\hline & \multicolumn{2}{|c|}{ TUNEL } & \multicolumn{2}{|l|}{$p 53$} & \multicolumn{2}{|c|}{$b c l-2$} & \multicolumn{2}{|c|}{$b a x$} & \multicolumn{2}{|c|}{ TUNEL } & \multicolumn{2}{|c|}{$p 53$} & \multicolumn{2}{|c|}{$b c l-2$} & \multicolumn{2}{|c|}{$b a x$} \\
\hline & $f$ & $e$ & $f$ & $e$ & $f$ & $e$ & $f$ & $e$ & $f$ & $e$ & $f$ & $e$ & $f$ & $e$ & $f$ & $e$ \\
\hline 1 & + & + & - & + & + & + & - & + & - & + & - & - & - & - & + & + \\
\hline 2 & + & + & - & + & - & + & - & + & + & + & - & - & - & - & + & + \\
\hline 3 & + & + & - & - & $+/-$ & + & - & + & + & + & - & - & - & - & - & + \\
\hline 4 & + & + & - & + & - & + & - & + & + & + & - & - & - & - & + & + \\
\hline 5 & - & + & - & + & - & + & - & + & + & + & - & - & - & - & - & + \\
\hline 6 & + & + & - & + & - & + & - & + & - & + & - & - & - & - & - & + \\
\hline 7 & - & + & - & - & - & + & - & + & - & + & - & - & - & - & - & + \\
\hline 8 & + & + & - & - & - & + & - & + & - & + & - & - & - & - & - & + \\
\hline 9 & + & + & $+/-$ & + & + & + & - & + & + & + & - & - & - & - & - & - \\
\hline 10 & + & + & - & - & + & + & - & + & + & + & - & - & - & - & - & + \\
\hline 11 & + & + & - & - & - & + & - & + & + & + & - & - & - & - & - & + \\
\hline 12 & + & + & - & + & - & + & - & + & - & + & - & - & - & - & + & + \\
\hline 13 & + & + & - & + & + & + & - & + & $+/-$ & + & - & - & - & - & - & + \\
\hline 14 & + & + & - & - & - & + & - & + & + & + & - & - & - & - & - & + \\
\hline 15 & + & + & - & + & + & + & - & + & + & + & - & - & - & - & - & + \\
\hline
\end{tabular}

$\mathrm{f}=$ fibrous layer; $\mathrm{e}=$ epithelial layer. 


\section{Normal conjunctiva}
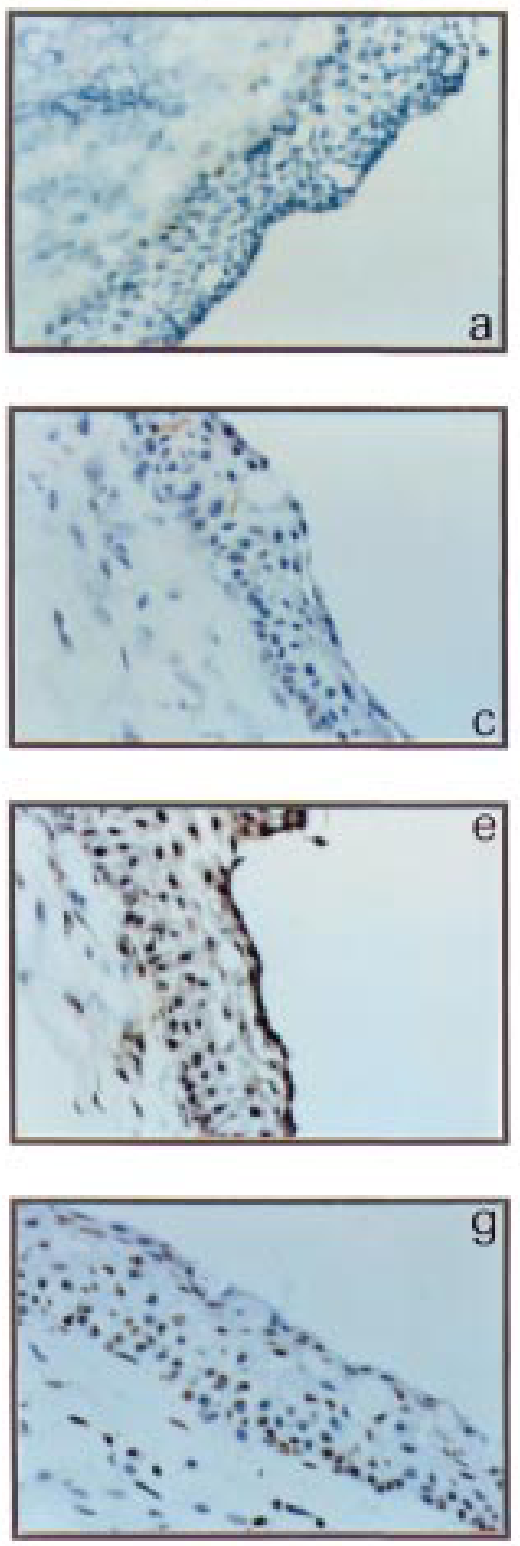

\section{Pterygium}
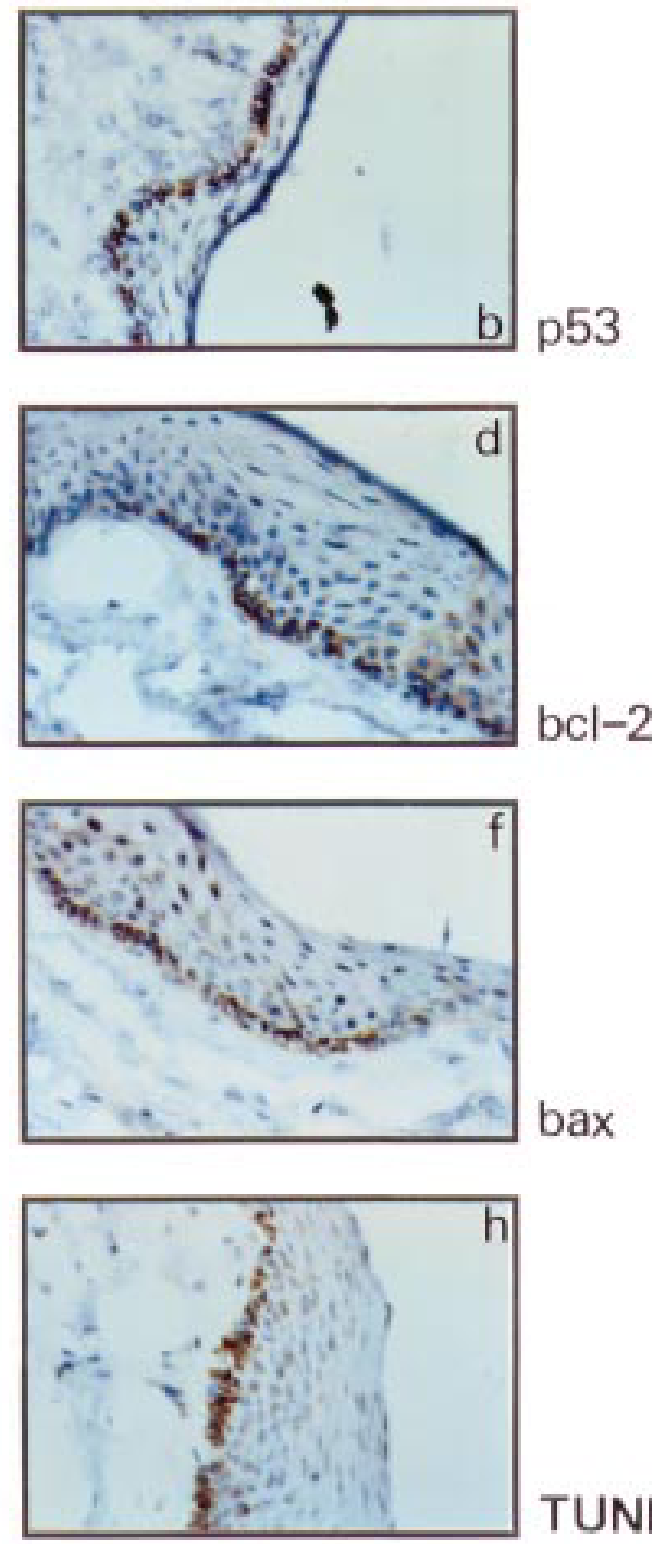

TUNEL

Figure 1 Immunohistochemical analysis of normal conjunctiva and pterygium. Specimens of normal conjunctiva and pterygium were stained with antibodies directed against $p 53(a, b) ; b c l-2(c, d) ;$ bax $(e, f)$, and DNA breaks (TUNEL) $(g, h)$. Normal conjunctiva $(a, c, e, g)$ and pterygium $(b, d, f, h)$ shown here are from one patient. Positive cells stain brown. Original magnification $\times 100$.

(Table 1). TUNEL positive cells in the fibrovascular layer were most commonly present as scattered isolated cells.

P53 ANALYSIS

Analysis of overexpression of the p53 protein was undertaken with the monoclonal antibody DO7, an antibody directed against an epitope located between amino acids $19-26$ of the p53 protein, and able to detect both wild type and mutant forms of the protein. Positive staining was detected in $60 \%(9 / 15)$ of pterygia samples. In contrast, no detectable expression was seen in any of the normal conjunctival specimens from the same eyes (Table 1, Fig 1a) a result different from our previous observations using monoclonal antibody pAb $240 .{ }^{4}$
Again in the epithelial layer of the pterygia specimens expression of p53 was noted predominantly in the basal layer of epithelial cells, although in some cases scattered staining was also noted in isolated epithelial cells in the width of the epithelial layer. No p53 expression was seen in the fibrovascular layer of either pterygia or normal conjunctival specimens.

BCL-2 ANALYSIS

Significant levels of bcl-2 staining were observed in all pterygia epithelia, and again staining was noted predominantly in the basal epithelial layer of cells (Fig 1d), although some positivity was noted through out the thickness of the layer in isolated cases. Normal conjunctival specimens showed no evidence of bcl-2 
expression (Fig 1c). The fibrovascular layer displayed no bcl-2 reactivity in either pterygia or normal conjunctivae.

\section{BAX ANALYSIS}

Significant levels of bax positivity were observed in all pterygia and normal conjunctival epithelial layers (Fig 1e, f). In the pterygia specimens light bax staining was noted throughout the thickness of the pterygia epithelial layer, while significant staining was again noted predominantly in the basal layer of cells of the pterygia epithelia (Fig 1f). In contrast, bax staining was detected at significant levels throughout the thickness of the epithelial layer of the normal conjunctival specimens, and the heaviest staining was seen in the outermost layer of cells of the normal conjunctival specimens (Fig 1e). No bax positivity was noted in the fibrovascular layer of pterygia samples. Bax positive cells were noted in $26 \%$ of normal conjunctival fibrovascular layers.

\section{Discussion}

Epithelial tissues are believed to maintain homeostasis by a tight regulation between cellular proliferation and cellular apoptosis, whereby cellular apoptosis represents the normal, programmed cell death of a cell that has reached the end of its life cycle. ${ }^{16}$ In common with some types of neoplastic growths,${ }^{17}$ evidence has shown that rates of cellular proliferation in pterygia samples are similar to rates found in the normal conjunctival surface $^{8}$ suggesting that pterygia may represent a failure of appropriate apoptosis.

Apoptosis as a form of cell death was first defined as being distinct from necrotic cell death by Kerr and co-workers in $1972 .{ }^{18}$ It is known that in contrast with necrosis, which is a passive event, cellular apoptosis requires both energy and the concerted action of a cascade of genes. ${ }^{19}$ In particular, it is believed that progress down an apoptotic pathway is regulated by the expression of genes that either promote or inhibit apoptosis. Inhibitors of apoptosis are believed to include gene such as bcl-2 and bcl-xl, ${ }^{19}$ while promoters of apoptosis include other genes such as bax, bad, bak, and bcl-xs. ${ }^{19}$

The apoptosis inhibitor bcl-2 is known to form heterodimers with apoptosis promoting genes, ${ }^{20} 21$ and in particular it is believed that it is the ratio of bcl-2 to bax that determines the fate of the cell..$^{21}$ If bax is in excess, all of the available apoptosis inhibiting bcl-2 is bound, and the cell progresses down an apoptotic pathway. If bcl-2 is in excess, all of the apoptosis promoting bax is bound, and the cell is protected against apoptosis. Interestingly, both of these genes are transcriptionally regulated by the p53 tumour suppressor gene, and p53 inhibits the expression of bcl-2 and promotes the expression of bax. ${ }^{22} 23$

Cells that undergo apoptosis show a characteristic range of features that discriminate from cells dying from necrosis including shrinkage of cell volume, chromatin margination, and DNA fragmentation. ${ }^{19}$ DNA fragmentation occurs as a result of enzymatic cleavage of
DNA at the nucleosomes, and results in a characteristic DNA ladder when genomic DNA is extracted from cells undergoing apoptosis and analysed by gel electrophoresis. ${ }^{19}$ The characteristic DNA breaks result in free 3'hydroxyl groups on the DNA and these free hydroxyl groups are now considered characteristic markers of cells undergoing apoptosis, and can be detected by terminal deoxynucleotide transferase (TdT) mediated nick end labelling. ${ }^{14}$

In the normal conjunctival specimens examined here, we find that bax is expressed throughout the thickness of the epithelial layer, although expression is particularly high in the outermost cells of the epithelial layer. Coupled with this we note apoptotic cells also throughout the thickness of the conjunctival epithelium. The results here are consistent with a model of conjunctival cell turnover which is driven by bax mediated apoptosis. Bax is transcriptionally regulated by the p53 tumour suppressor gene..$^{23}$ In normal circumstances p53 is present at levels undetectable by normal immunohistochemical methods, ${ }^{24}$ and p53 is normally only detectable when stabilised through a variety of mechanisms such as point mutation, mdm2 amplification, or protein sequestration. ${ }^{25}$ In each of these cases it is believed that p53 becomes fully or partially inactivated.

In a previous report ${ }^{4}$ we have noted the overexpression of $\mathrm{p} 53$ as detected with monoclonal antibody pAb240 in both pterygium and normal superior bulbar conjunctivae of pterygium eyes. As such these two reports would appear to be inconsistent. However, wild type p53 is a labile protein that can exist in different conformations ${ }^{26}$ as well as different isoforms, ${ }^{27}$ and transcriptionally active and inactive p53 are not always recognised by the same antibodies. As such our results suggest that normal conjunctivae from pterygia eyes and pterygia specimens contain pools of both transcriptionally active and inactive p53. The fact that different pools of $\mathrm{p} 53$ may exist in conjunctival and pterygia specimens explains the discrepant results seen by different groups with respect to p53 in that each group has employed different antibodies. $^{4528}$

In the pterygia specimens examined here we note $\mathrm{p} 53$ positive cells in the basal layer of the epithelium of the pterygia specimens, again suggestive of protein stabilisation and inactivation. The pattern is again different from that noted with monoclonal antibody pAb $240,{ }^{29}$ again consistent with different pools of p53 existing within the conjunctival/pterygium cells. The aberrant expression of $\mathrm{p} 53$ in these cells is coupled with expression of bcl-2, suggestive of a release of transcriptional fidelity by p53. Bax is still expressed in these cells indicative that some degree of wild type p53 expression is still occurring. In the pterygium specimens apoptotic cells are restricted with respect to the spatial distribution consistent with the anti-apopototic effect of bcl-2 expression.

The results presented in this report provide the first examination of cellular apoptosis and 
the genetic events that regulate it in both histologically normal superior bulbar conjunctivae from pterygium eyes as well as pterygium specimens. Taken together the results point to aberrant regulation of apoptosis in pterygium specimens. Whether pterygium results directly from the disruption of normal cellular apoptosis, or whether another lesion in the cell leads to disruption of the apoptotic pathways cannot at this point be discriminated.

Currently, the mainstay of treatment for pterygia is surgical excision. However, the high recurrence rate and relatively high cost in terms of surgical management mean that nonsurgical methods of treatment for pterygia would be beneficial, particularly in countries where medical resources are not so well developed. For this, treatment strategies which are directed at restoring correct cellular apoptosis may provide a fruitful area of exploration.

This work was supported by research grants RSCH/97/007 from Tan Tock Seng Hospital and NMRC/0039/1994 from the National Medical Research Council.

1 Spraul CW, Grossniklaus HE. Tumors of the cornea and conjunctiva. Curr Opin Ophthalmol 1996;7:28-34.

2 Hill JC, Maske R. Pathogenesis of pterygium. Eye 1989;3:218-26.

3 Clear AS, Chirambo MC, Hutt MS. Solar keratosis, pterygium, and squamous cell carcinoma of the conjunctiva in Malawi. Br F Ophthalmol 1979;63:102-9.

4 Tan DT, Lim AS, Goh HS, et al. Abnormal expression of the p53 tumour suppressor gene in the conjunctiva of patients with pterygium. Am f Ophthalmol 1997;123:404-5.

5 Dushku N, Reid TW. P53 expression in altered limbal basal cells of pingueculae, pterygia, and limbal tumors. Curr Eye

6 Tan DT, Chee SP, Dear KB, et al. Effect of pterygium morphology on pterygium recurrence in a controlled trial comparing conjunctival autografting with bare sclera excision Arch Ophthalmol 1997;115:1235-40.

7 Jap A, Chan C, L Li, et al. Conjunctival rotation autograft for pterygium. Ophthalmology 1999;106:67-71.

8 Karukonda SR, Thompson HW, Beuerman RW, et al. Cell cycle kinetics in pterygium at three latitudes. Brf Ophthal mol 1995;79:313-7.

9 Mackenzie FD, Hirst LW, Battistutta D, et al. Risk analysis in the development of pterygia. Ophthalmology 1992 99:1056-61.
10 Moran DJ, Hollows FC. Pterygium and ultraviolet radiation: a positive correlation. Br f Ophthalmol 1984;68 343-6.

11 Taylor HR. Ultraviolet radiation and the eye: an epidemiologic study. Trans Am Ophthalmol Soc 1989;87:802-53.

12 Spandidos DA, Sourvinos G, Kiaris H, et al. Microsatellite instability and loss of heterozygosity in human pterygia. $\mathrm{Br}$ f Ophthalmol 1997;81:493-6.

13 Detorakis ET, Sourvinos G, Tsamparlakis J, et al. Evaluation of loss of heterozygosity and microsatellite instability in human pterygium: clinical correlations. Br f Ophthalmol 1998;82:1324-8.

14 Gavrieli Y, Sherman Y, Ben-Sasson SA. Identification of programmed cell death in situ via specific labelling of nuclear DNA fragmentation. F Cell Biol 1992;119:490501.

15 Hsu S-M, Raine L, Fanger H. Use of avidin-biotinperoxidase complex (ABC) in immunoperoxidase techniques. F Histochem Cytochem 1981;29:577-80.

16 DeLong MJ. Apoptosis: a modulator of cellular homeostasis and disease states. Ann NY Acad Sci 1998; 842:82-90.

17 Eastman A. Survival factors, intracellular signal transduction, and the activation of endonucleases in apoptosis. Sem Cancer Biol 1995;6:45-52.

18 Kerr JF, Wyllie AH, Currie AR. Apoptosis: a basic biological phenomenon with wide-ranging implications in tissue cal phenomenon with wide-ranging
kinetics. Br f Cancer 1972;26:239-57.

19 Savitz SI, Rosenbaum DM. Apoptosis in neurological disease. Neurosurgery 1998;42:555-72.

20 Oltvai ZN, Milliman CL, Korsmayer SJ. Bcl-2 heterodimerizes in vivo with a conserved homolog, bax, that accelerates programmed cell death. Cell 1993;74:609-19.

21 Yang E, Zha J, Jockel J, et al. Bad, a heterodimeric partner for Bcl-XI and Bcl-2, displaces Bax and promotes cell death. Cell 1995;80:285-91.

22 Miyashita T, Harigai M, Hanada M, et al. Identification of a p53-dependent negative response element in the bcl-2 gene. Cancer Res 1994;54:3131-5.

23 Miyashita T, Reed JC. Tumor suppressor p53 is a direct transcriptional activator of the human bax gene. Cell 1995; 8:293-9.

24 Rodrigues NR, Rowan A, Smith ME, et al. p53 mutations in colorectal cancer. Proc Natl Acad Sci USA 1990;87:7555-9.

25 Vogelstein B, Kinzler KW. p53 function and dysfunction. Cell 1992;70:523-6.

26 Selkirk JK, He C, Patterson RM, et al. Tumor suppressor p53 gene forms multiple isoforms: evidence for single locus origin and cytoplasmic complex formation with heat shock proteins. Electrophoresis 1996;17:1764-71.

27 Milner J, Medcalf EA. Cotranslation of activated mutant p53 with wild type drives the wild-type p53 protein into the mutant conformation. Cell 1991;65:765-74.

28 Onur C, Orhan D, Orhan M, et al. Expression of $\mathrm{p} 53$ protein in pterygium. Eur $\mathcal{F}$ Ophthalmol 1998;8:157-61.

29 Gannon JV, Greaves R, Iggo R, et al. Activating mutations in p53 produce a common conformational effect. A monoclonal antibody specific for the mutant form. EMBO $\mathcal{f}$ 1990;9:1595-602. 